\title{
Literature Review: Teknik Relaksasi untuk Penerimaan Diri Pasien Kanker Payudara
}

\author{
Ni Made Merlin ${ }^{1}$, Anggorowati ${ }^{2}$, Chandra Bagus Ropyanto ${ }^{3}$, Antonius Rino Vanchapo ${ }^{4}$ \\ ${ }^{1,4}$ Program Studi Keperawatan, STIKes Maranatha Kupang, Indonesia \\ ${ }^{2,3}$ Departemen Keperawatan, Universitas Diponegoro Semarang, Indonesia \\ Email: nimademerlin@maranatha-ntt.ac.id
}

\begin{abstract}
Literatur Review: The Relaxation Technique for Self-Acceptance in Breast Cancer Patient. Breast cancer patients experience low self-acceptance and some of the experiencing psychological problems but not a lot of research to increasing self-acceptance. Additional intervention is needed to improve the effectiveness to increase self-acceptance. Technique relaxation is especially related because easy and quick to learn, it involves no risk, does not need use or purchased equipment and can be used on its own and immediately to tiredness and ill patients. This paper offers a literature review assessing the implications of previous studies order to create evidence-based decisions about the possibility to use of relaxation techniques with adult breast cancer patient for low self-acceptance. The Science Direct, EBSCOhost, Pubmed, DOAJ, Google Scholar database were searched in 2017 in orders to replied two questions: are relaxation technique effective to increase self-acceptance in breast cancer patients, and implications the previous investigation to future research concerning increase self-acceptance in breast cancer patients? Four articles included in the literature review. The relaxation technique for breast cancer patients with low self-acceptance is statically significant, and good evidence-based to practice. Some use of relaxation techniques in this study needs clarification as to whether it can be used directly or need to learn. Procedures in the collection of data in the articles also need to be assessed. In this literature review explain 4 relaxation technique to use for increasing selfacceptance in breast cancer, there are self-forgiveness, meditation, tai-chi, reflection, prayer, mindfulness. This literature review can be used as the basis for the decision to use relaxation techniques for increasing self-acceptance in the breast cancer patient.
\end{abstract}

Keywords: Breast cancer, Relaxation technique, Self-acceptance

\begin{abstract}
Abstrak: Teknik Relaksasi untuk Penerimaan Diri Pasien Kanker Payudara. Pasien kanker payudara rata-rata mengalami penerimaan diri yang rendah dan beberapa dari mereka mengalami masalah psikologis. Masalah psikologis yang dialami oleh pasien kanker payudara salah satunya penerimaan diri terkait penyakit kanker payudara yang diderita. Efek dari masalah tersebut sangat merugikan pasien namun tidak banyak penelitian untuk meningkatkan penerimaan diri. Intervensi tambahan diperlukan untuk meningkatkan penerimaan diri. Salah satunya, teknik relaksasi karena mudah dan cepat dipelajari, tidak memiliki risiko, tidak perlu menggunakan atau membeli peralatan, dapat dipraktekkan secara mandiri kapanpun diinginkan. Makalah ini menawarkan literatur yang menilai implikasi penelitian sebelumnya sebagai Evidence-Based kemungkinan penggunaan teknik relaksasi pada pasien kanker payudara yang mengalami penerimaan diri rendah. The Science Direct, EBSCOhost, Pubmed, DOAJ, database Google Cendekia dicari pada tahun 2017 untuk menjawab dua pertanyaan: apakah teknik relaksasi efektif untuk meningkatkan penerimaan diri pada pasien kanker payudara, dan implikasi penelitian sebelumnya terhadap penelitian di masa depan mengenai peningkatan penerimaan diri pada pasien kanker payudara? Empat artikel ditinjau dalam literatur review ini. Teknik relaksasi untuk pasien kanker payudara dengan penerimaan diri yang rendah adalah memiliki efek signifikan secara statistik, dan berdasarkan bukti yang baik untuk praktik. Beberapa penggunaan teknik relaksasi dalam penelitian ini perlu diklarifikasi, apakah itu dapat digunakan secara langsung atau perlu belajar. Prosedur dalam pengumpulan data dalam artikel juga perlu dinilai. Dalam ulasan literatur ini menjelaskan 4 teknik relaksasi yang digunakan untuk meningkatkan penerimaan diri pada kanker payudara, ada pengampunan diri, meditasi, tai-chi, refleksi, doa, perhatian. Ulasan literatur ini dapat digunakan sebagai dasar keputusan menggunakan teknik relaksasi untuk meningkatkan penerimaan diri pada pasien kanker payudara.
\end{abstract}

Kata kunci: Kanker payudara, Teknik relaskasi, Penerimaan diri 



\section{PENDAHULUAN}

Pasien kanker payudara rentan mengalami penerimaan diri yang rendah akibat efek fisik dan psikologis dari kanker payudara yang dialami. Hasil penelitian menunjukkan bahwa 152 dari 231 pasien atau sebanyak $68 \%$ pasien kanker payudara memiliki penerimaan diri rendah hingga sedang (Cipora, Koeczny \& Sobieszczanski, 2018), hasil ini menunjukkan bahwa pasien kanker payudara tidak dapat menerima dirinya sendiri karena dampak yang mereka alami. Data primer yang diperoleh dari salah satu rumah sakit di Semarang menyatakan bahwa $68 \%$ pasien kanker payudara yang menjalani pengobatan kanker memiliki penerimaan diri yang rendah, bahkan $10 \%$ dari pasien tersebut memutuskan untuk berhenti dari rejimen terapi yang disepakati.

Hasil penelitian Cipora, 2018 menyimpulkan bahwa masalah psikologis yang sering dialami pasien kanker payudara berkaitan dengan kekuatiran penyakit, ketidakaktifan dimasa depan, dan ketakutan akan kematian dapat menyebabkan stres, depresi, kecemasan, perasaan kurang utuh dan juga karena program perawatan yang sangat lama dapat mempengaruhi penerimaan diri terhadap penyakit (Cipora, Koeczny \& Sobieszczanski, 2018). Lebih lanjut, keluhan masalah fisik seperti mual, muntah, alopesia, stomatitis, penurunan berat badan, kelelahan, dan perubahan status hematologi juga dapat menyebabkan rendahnya penerimaan diri (Black, J. M., \& Hawks, 2009).

Hasil wawancara pada salah satu perawat di salah satu rumah sakit Kota Semarang menyatakan bahwa pasien dengan penerimaan diri yang rendah biasanya memiliki banyak keluhan yaitu: kurang puas dengan dirinya sendiri, mual, muntah, kurang tidur, cemas, sakit, marah, depresi, hingga isolasi sosial. Dampak dari rendahnya penerimaan diri dapat memengaruhi kesehatan mental dan mendorong aktivitas pasca-trauma, yang akan memengaruhi proses penyembuhan. Salah satu dampak yang dapat terjadi pada pasien dengan penerimaan diri yang rendah adalah kegagalan pengobatan, dan beberapa bulan kemudian pasien kembali dengan kondisi yang lebih parah. Penerimaan diri yang rendah dapat memengaruhi emosi negatif karena ketidakmampuan untuk mengatasi rasa sakit yang dialami (Cipora, Koeczny \& Sobieszczanski, 2018). Pasien dengan penerimaan diri yang rendah lebih cenderung mengalami stres, kurang percaya diri / kemampuan kontrol, kurangnya motivasi untuk melawan penyakit dan manajemen kesehatan yang buruk (Tang, S. T.,
Chang, W. C., Chen, J. S., Chou, W. C., Hsieh, C. H., \& Chen, 2016; Zielazny et al., 2013).

Hasil penelitian oleh Tang et al tahun 2016 dengan judul Running head: Penerimaan diri dan faktor terkait menyatakan bahwa pasien kanker payudara dengan penerimaan diri rendah akan mengalami kehilangan kepercayaan diri, rendah diri, gangguan kesehatan mental, dan kurangnya minat untuk mengimplementasikan program terapi yang telah dijadwalkan. Penerimaan diri yang rendah dapat mempercepat atau memperburuk prognosis penyakit, ketergantungan fungsional, kecemasan, merasa menjadi beban bagi orang lain dan juga tidak dapat menerima kematian mereka yang akan datang (Tang et al., 2016).

Dampak dari rendahnya penerimaan diri ditunjukkan oleh pasien yang memilih keluar dari proses terapi seperti kemoterapi yang dilakukan sampai beberapa bulan kemudian pasien datang dengan kondisi yang sangat parah seperti kondisi payudara yang memburuk, kemerahan yang membengkak dari payudara menyebar ke lengan pasien, tidak bisa tidur nyenyak di malam hari, takut mati, dan merasa seperti mereka ingin mati. Dampak penerimaan diri sangat mempengaruhi kondisi kesehatan pasien sehingga diperlukan intervensi yang dapat membantu pasien dalam penerimaan diri terkait dengan kanker payudara.

Penerimaan diri yang baik ditandai dengan memiliki pandangan positif tentang diri, mengakui dan menerima berbagai aspek diri kita termasuk kualitas baik dan buruk yang ada, menuju kehidupan yang telah mereka jalani (Rizkiana, 2012). Salah satu intervensi yang dapat dilakukan untuk meningkatkan penerimaan diri adalah teknik relaksasi. Beberapa intervensi termasuk teknik relaksasi yaitu pencitraan, relaksasi progresif, biofeedback, self-hypnosis, meditasi (seperti tai chi dan yoga) dan latihan pernapasan dalam (Tighe, 2016).

Tujuan dari tekniknya serupa: untuk menghasilkan respons alami dari relaksasi dan peningkatan perasaan sejahtera serta motivasi untuk sembuh. Namun, terlepas dari meningkatnya jumlah uji klinis untuk relaksasi, belum ada kesimpulan yang konsisten tentang efektivitas relaksasi untuk penerimaan pada pasien dengan kanker, sebagaimana dibuktikan dalam penelitian sebelumnya.

\section{METODE}

Penulis mengikuti Buku Pegangan Cochrane untuk Systematic Reviews of Interventions(Schunemann et al., 2008) untuk 
literatur review ini dipilih dari Randomized Control Trials (RCTs), quasy-eksperimen, one group pretest-posttest, randomized trial untuk mengeksplorasi efek teknik relaksasi pada penerimaan pada pasien kanker payudara. Kami menggunakan The Preferred Reporting Items for Systematic Reviews and Meta-Analyses group (PRISMA) sebagai dasar untuk item pelaporan literatur review ini (David Moher, Alessandro Liberati; Jennifer Tetzlaff, 2009).

Artikel yang termasuk dalam tinjauan pustaka diterbitkan dari Januari 2000 hingga Desember 2017, dan ditemukan melalui pencarian berbasis komputer di Science Direct, Ebsco, PubMed, CINAHL, Direktori Jurnal Akses Terbuka (DOAJ), Google Cendekia. Kami melakukan pencarian menggunakan judul subjek medis (MeSH) berikut dan kata-kata teks: (('acceptance' [MeSH] OR 'accept*' OR 'selfacceptance' OR 'Self-awareness')) AND (('breast cancer' [MeSH] OR 'Ca-Mamae' OR 'cancer')) AND (('relaxation technique' [MeSH] OR 'relax' OR 'relaxation method' OR 'relaxation training' OR 'relaxation exercise(s)' OR 'applied relaxation' OR 'PMR' OR 'progressive relaxation' OR 'relaxation desensitization' OR 'Mindfulness' OR 'guided imagery' OR ‘meditation' OR 'imagery')) .

\section{Kriteria Seleksi}

1) Kriteria pemilihan/ kriteria inklusi (menggunakan PICO) adalah sebagai berikut:

a. Patient: Subjek terdaftar dengan diagnosis kanker payudara berusia 18 tahun atau lebih tua.

b. Intervention: teknik relakasi.

c. Comparison: perawatan biasa, pengobatan alternatif atau tidak ada kelompok perlakuan.

d. Outcomes: termasuk penerimaan diri.

e. Desain studi dalam RCT, quasyeksperimental, study investigated .

f. Penelitian dilaporkan dalam Bahasa Indonesia atau Bahasa Inggris

g. Full-text pdf

2) Kriteria ekslusi adalah sebagai berikut:

a. Editorial, lembar opini, ulasan dan catatan

b. Teknik relaksasi sebagai kombinasi dengan perawatan lain

c. Teknik relaksasi sebagai pembanding (bukan intervensi utama)

\section{HASIL}

Tahap pertama yaitu identifikasi awal pada database Science Direct, Ebscohost, Pubmed, Doaj, Google Scholar sebanyak 547 artikel dan berdasarkan daftar pustaka dalam artikel sebanyak 3. Tahap kedua screening didapatkan terdapat duplikasi dari judul dan juga abstrak sebanyak 32 artikel yang harus dikelurakan, 61 artikel tidak tersedia dalam bentuk full-text pdf tersisa 80 artikel. Tahap ketiga eligibility 80 artikel direview dan dilihat kelayakan sesuai dengan kriteria inklusi serta eksklusi yang telah ditetapkan. 73 artikel yang dikeluarkan dengan alasan : teknik relaksasi tidak menjadi intervensi utama sebanyak 46 artikel, tidak mengukur penerimaan diri sebanyak 19 artikel, masuk dalam kriteria eksklusi sebanyak 8 artikel. Tahap keempat yaitu included: tersisa 7 artikel yang dapat di review tapi 3 dikeluarkan karena termasuk juga dalam pengukuran studi kualititatif. Tahap penilaian artikel terlihat pada gambar 1. Hasil akhir artikel yang direview sebanyak 4 artikel.

Artikel pertama dengan judul "Restore: The Journey Toward Self-Forgiveness: A Randomized Trial of Patient Education on Selfforgiveness in cancer patients and caregiver" oleh Tousaint, et al pada tahun 2014 dengan menggunakan intervensi singkat psiko-spiritual untuk memberi semangat dan memaafkan diri sendiri. Hasil dari penelitian ini didapatkan bahwa responden mengalami peningkatan penerimaan diri dan pengampunan diri (Toussaint, Barry, Bornfriend, \& Markman, 2014).

Artikel kedua yang direview adalah "Program Pasien Pandai untuk Meningkatkan Optimisme Pasien Kanker Payudara oleh Saniatuzzulfa pada tahun 2015. Intervensi yang ditawarkan merupakan intervensi dengan beberapa tahap. Tahap pertama latihan relaksasi, tahap kedua mengenal diri sendiri, tahap ketiga berkomitmen untuk kesembuhan dan tahap keempat adalah tindakan nyata sebagai bentuk perubahan perilaku. Hasil yang didapatkan adalah optimisme pasien meningkat seiring dengan penerimaan diri pasien (Saniatuzzulfa, Retnowati, \& Magister Profesi Psikologi Fakultas Psikologi Uniersitas Gadjah Mada, 2015).

Artikel ketiga adalah "mindfulness based cancer recovery the development of an evidencebased psychosocial oncology intervention oleh Speca, et al pada tahun 2014. Intervensi yang ditawarkan adalah mindfullnes dengan kombinasi meditasi, yoga dan latihan berbasis tubuh. Hasil yang didapatkan pasien menyatakan insomnia, 
stres, depresi dan penerimaan diri semakin baik (Speca, Carlson, Mackenzie, \& Angen, 2014).

Artikel keempat yang direview adalah "Tai Chi Chuan, health-related quality of life and selfesteem: A randomized trial with breast cancer survivors oleh Mutia, et al pada tahun 2004. Intervensi yang ditawarkan berupa tai chi yang diberikan berdasarkan Chi Kung Fundamental
Stationary. Intervensi yang diberikan juga berupa kombinasi dengan meditasi. Hasil yang didapatkan adalah kualitas hidup pasien meningkat dan penerimaan diri diukur dengan menggunakan kuesioner harga diri didapatkan bahwa responden mengalami penerimaan diri yang baik (Mustian et al., 2004).

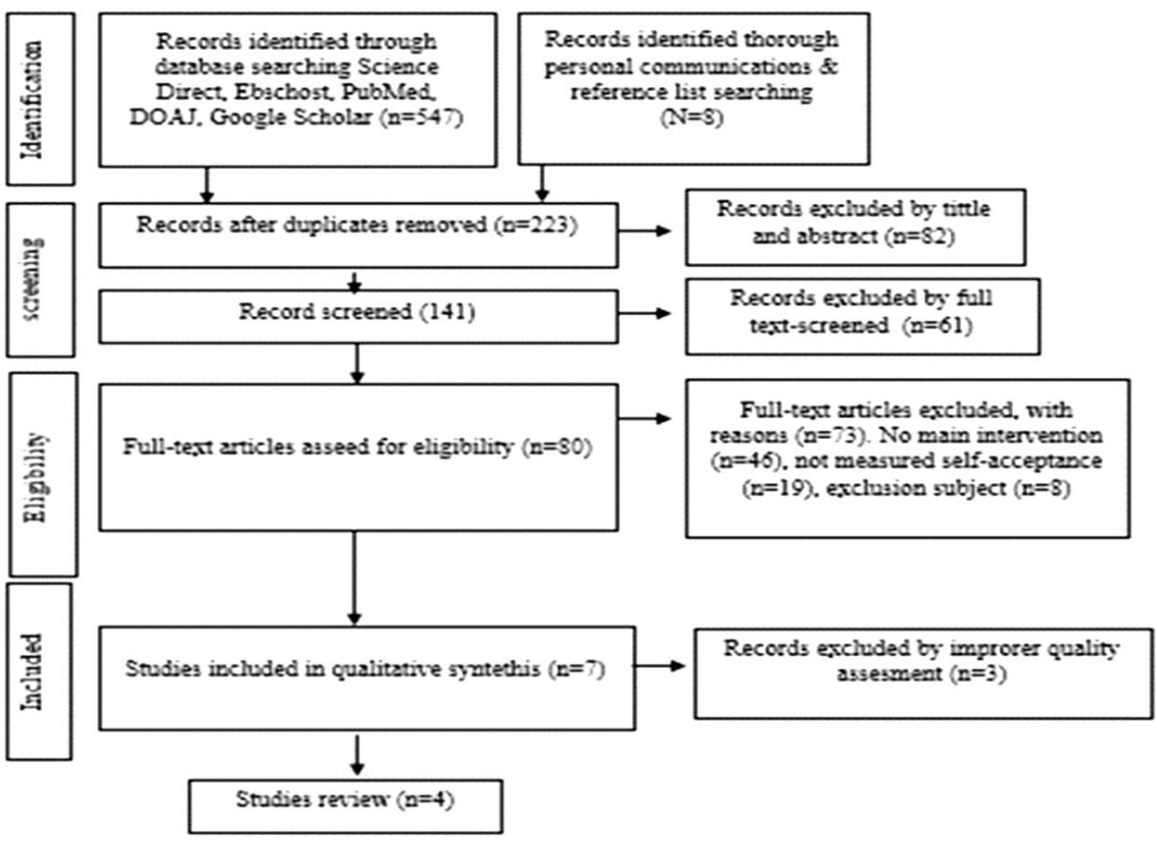

Gambar 1. Hasil Pencarian Literatur Dengan Menggunakan Metode PRISMA

\section{PEMBAHASAN}

Pada bagian ini, 4 artikel tersebut diidentifikasi dan menlihat implikasi dari desain penelitian untuk investigasi di masa depan dengan rendahnya penerimaan diri pasien kanker payudara. Empat aspek yang dianalisis dalam literatur review ini adalah efek, jenis teknik relaksasi, instruksi dan panduan dalam menggunakan teknik, pengukuran, dan hasil.

\section{Efek}

Efek peningkatan penerimaan diri yang signifikan secara statistik juga terlihat dalam studi oleh Tousaint, (2014) dan Speca, (2014). Pengaruh program statistik PANDAI tidak signifikan karena waktu implementasi yang singkat, jumlah partisipasi yaitu data kurang beragam atau bervariasi. Namun, manfaat dari program PANDAI adalah pasien memiliki pengetahuan, merasa lebih termotivasi untuk hidup sehat, menerima kondisinya sendiri, dan lebih bersemangat untuk pulih dari kanker. Para penulis mengaitkan ukuran sampel dengan artikel ini kurang bervariasi, penentuan waktu intervensi untuk program Journey dan PANDAI terlalu dini.

Teknik relaksasi yang digunakan dalam studi literatur ini menunjukkan hasil yang baik dalam meningkatkan penerimaan diri pasien kanker payudara. Namun, beberapa studi melakukan pemberian berbagai teknik relaksasi sebagai intervensinya atau dengan kata lain tidak melaksanakan intervensi tunggal.

\section{Tipe Teknik Relaksasi}

Penelitian dari Tousaint (2014) menjelaskan intervensi dalam penelitian ini meliputi teknik relaksasi terdiri dari doa, refleksi, meditasi, dan penulisan ekspresif. Pendidikan memaafkan diri sebenarnya meningkatkan penerimaan diri pada pasien kanker payudara tetapi tidak meningkatkan tindakan dan perasaan memaafkan diri sendiri.

Program Pasien Pandai memberikan manfaat bagi responden dari materi yang diperoleh selama mengikuti program PANDAI, seperti latihan relaksasi. Relaksasi berfungsi sebagai keterampilan mengatasi ketika seseorang 
mengalami stres, dapat mencegah beberapa efek negatif dari stres, dan meningkatkan sistem kekebalan terhadap kanker (Saniatuzzulfa, Retnowati, 2015).

Intervensi MBCR Mindfullnes dengan prinsip relaksasi termasuk meditasi, hatha-yoga dan latihan berbasis tubuh memberikan efek yang positif untuk penerimaan diri pasien kanker payudara. Teknik SET pada MBCR sangat membantu pasien kanker payudara dalam mengatasi masalah psikologis pada tahap awal diagnosis dan metastasis kanker payudara (Speca, Carlson, Mackenzie, \& Angen, 2014).

Penelitian dari Mustian (2004) meneliti tentang relaksasi Tai Chi Cuan termasuk peregangan, pemanasan dan selama 10 menit terakhir responden menjalani latihan Tai Chi, citra diri dan meditasi. TCC berpotensi untuk pasca perawatan, modalitas rehabilitasi terapeutik untuk meningkatkan kualitas hidup pasien kanker payudara dan juga harga diri pasien.

Dalam jenis ulasan teknik relaksasi untuk meningkatkan penerimaan diri pada pasien kanker payudara dapat menggunakan beberapa teknik relaksasi. Teknik relaksasi yang paling bagus untuk diterapkan yaitu teknik relaksasi meditasi.

\section{Instruksi dan Bimbingan}

Faktor penting yang harus dilihat sebelum menggunakan teknik relaksasi adalah durasi perawatan, sesi perawatan, dan bimbingan. Penelitian dari Tousaint (2014) menggunakan teknik relaksasi dengan intervensi singkat. Intervensi ini membutuhkan 90 menit dalam satu sesi pemberian sementara menunggu pengobatan kanker payudara dari rumah sakit. Instruksi penelitian ini diberikan secara verbal. Pengukuran sebelum dan sesudah intervensi dilakukan dengan segera setelah memberikan intervens.

Program PANDAI yaitu 4 tahap dalam 2 minggu (selama 120 menit). Tahap pertama dari program ini adalah latihan berbagi dan relaksasi. Tahap kedua adalah mengenal diri sendiri dan menerima untuk menumbuhkan kesadaran pasien dan membantu pasien menerima kondisi serta berbagai kesulitan yang dialami. Tahap ketiga adalah berkomitmen dan menetapkan tujuan hidup sesuai dengan kondisi kesehatan agar tujuan hidup tercapai. Tahap terakhir adalah tahap tindakan dimana pasien akan dinilai sebagai bentuk perubahan perilaku (Saniatuzzulfa et al., 2015).

Program MBSR diberikan hingga 8 minggu dengan estimasi waktu 2,5 jam per minggu dengan kapasitas 30 responden dalam sekali intervensi. Hasil yang diperoleh menunjukkan bahwa pemberian pada minggu pertama memberikan kemajuan pada peserta. Kegiatan intervensi MBSR yaitu meditasi duduk dan berjalan, yoga hata yang lembut, latihan berbasis tubuh. Instruksi ini diberikan secara verbal dan didaktik (refleksi dan diskusi dalam bentuk kelompok), pemecahan masalah dan keterampilan untuk alat pengajaran. Minggu keenam atau ketujuh responden memiliki retret tradisional (diskusi kelompok) hingga 6 jam.

Program Tai Chi dikelola oleh American College of Sports Medicine yang memiliki sertifikat kesehatan atau instruktur TCC. Dasar yang digunakan yaitu Chi Kung (Fundamentals TCC stasioner). Pemberian instruksi secara verbal dan visual. Intervensi tai chi diberikan sekitar 15 menit untuk TCC dan 10 menit terakhir dilatih untuk menarik napas panjang, meditasi, pencitraan, serta latihan pendinginan.

Instruksi dan panduan dalam menggunakan teknik relaksasi dalam studi literatur ini rata-rata menggunakan instruksi secara verbal dan menggunakan alat bantu buku. Salah satu intsruksi TCC menggunakan visual untuk menerapkan intervensinya. Berdasarkan study literatur yang dilakukan, untuk waktu pemberian teknik relaksasi terdiri dari 90 hingga 120 menit. Hasil yang didapatkan adalah dalam estimasi pemberian 90-120 menit teknik relaksasi pasien sudah merasakan dampak yang positif dan lebih siap untuk diberikan rejimen terapi untuk kanker.

\section{Alat Ukur}

Instrumen pengukuran penerimaan diri yang digunakan untuk penelitian Tousaint (2014) adalah Pasca-traumatic Cognition Inventory (PTCI). PTCI terdiri dari lima item sub skala untuk menilai penerimaan diri (Toussaint et al., 2014).

Skala AAQ untuk mengukur penerimaan dan tindakan (10 item) karena dimodifikasi untuk mengukur penerimaan diri dan tindakan dan tujuan dari program ini adalah agar pasien kanker memiliki pandangan positif tentang masa depan mereka, untuk lebih menerima kondisi mereka, dan untuk bertahan hidup dalam menghadapi penyakit mereka (Saniatuzzulfa et al., 2015).

Instrumen yang digunakan untuk meneliti penerimaan diri berbeda untuk setiap penelitian dalam literatur review ini. Kuesioner-kuesioner tersebut mengukur penerimaan diri, (harga diri, memaafkan diri dan pesimisme diri) (Mustian et al., 2004; Saniatuzzulfa et al., 2015; Speca et al., 2014; Toussaint et al., 2014). 
Penerimaan diri menurut Speca tidak sama dengan "menyerah" untuk mengobati penyakitnya, responden akan mengenali kondisi tubuhnya. Penerimaan diri juga akan meningkatkan motivasi pasien untuk mencoba pengobatan alternatif untuk kesembuhannya menurut (Speca et al., 2014).

Kuesioner yang digunakan untuk penerimaan diri dalam literatur ini dimodifikasi dan disesuaikan untuk tujuan penelitian masingmasing.

\section{SIMPULAN}

Penerimaan diri adalah salah satu aspek penting bagi kesehatan dan kesejahteraan pasien kanker payudara. Berdasarkan literatur studi, teknik relaksasi adalah salah satu intrevensi yang dapat digunakan dan memiliki risiko komplikasi yang rendah. Salah satu teknik relaksasi adalah meditasi yang sering digunakan untuk meningkatkan penerimaan diri pada pasien kanker payudara. Namun, ada bukti lain yang menunjukkan perlunya penelitian lebih lanjut untuk membuktikan intervensi tersebut. Perawat onkologi dapat memberikan intervensi relaksasi untuk meningkatkan penerimaan diri dan melatih pasien untuk melaksanakannya secara mandiri. Sebelum pemberian teknik relaksasi digunakan untuk meningkatkan penerimaan diri, sebaiknya dilakukan studi deskriptif untuk menggambarkan bagaimana penerimaan diri pasien kanker payudara sebelum diberikan teknik relaksasi.

Berdasarkan studi literatur yang diperoleh, pasien harus menerima satu intervensi dengan instruksi verbal sebelum melakukan teknik relaksasi. Jumlah waktu untuk memberikan intervensi disarankan sekitar 90 hingga 120 menit. Teknik relaksasi juga dapat diberikan sesuai dengan terapi mingguan untuk regim kanker.

Alat untuk menilai efek relaksasi terhadap penerimaan diri perlu dikembangkan dan divalidasi untuk digunakan pada pasien khususnya pasien kanker payudara. Kesamaan karakteristik atau status demografi pasien berdampak pada penerimaan diri ada lama menderita penyakit, terapi resimen dipegang pasien, sosial budaya, efek samping dari terapi rejimen kanker. Responden secara khusus menerima latihan tetapi hasilnya tidak menggeneralisasi responden untuk kurang menyetujui mode ini (Mustian et al., 2004).

Beberapa komponen penerimaan diri harus diperhatikan, yaitu sosial budaya, psikologi, status perkawinan, usia, jenis terapi yang diwajibkan, berapa lama kanker payudara terpengaruh. Data harus dikumpulkan selama intervensi dan pada tiga nilai: pre-test, post-test dan tindak lanjut.

Penilaian penerimaan diri adalah hasil utama untuk penelitian efek teknik relaksasi di masa depan. Instrumen yang penulis sarankan untuk menilai penerimaan diri adalah Skala AAQ untuk mengukur penerimaan dan tindakan (10 item) karena dimodifikasi untuk mengukur penerimaan dan disesuaikan dengan tujuan program.

Terapi rejimen untuk pasien kanker payudara dapat menghabiskan energi untuk melawan stres dari pasien sehingga penerimaan diri pasien akan turun. Solusi terbaik bagi pasien adalah bagaimana hal itu dapat meningkatkan proses penerimaan diri dengan menggunakan teknik relaksasi seperti napas dalam, peregangan, yoga, relaksasi, dan mendengarkan musik juga lingkungan pemulihan alami.

\section{DAFTAR PUSTAKA}

Black, J. M., \& Hawks, J. H. (2009). Medical surgical nursing clinical management for continuity of care (8th ed.). Philadelphia: W.B Saunderes Company.

Cipora, E., Konieczny, M., \& Sobieszczanski, J. (2018). Acceptance of illness by women with breast cancer. Annals of Agricultural Environtment Medicine, 23. https://doi.org/10.26444/aaem/75876

David Moher, Alessandro Liberati; Jennifer Tetzlaff, D. G. A. (2009). Academia and Clinic Annals of Internal Medicine Preferred Reporting Items for Systematic Reviews and Meta-Analyses: Annals of
Internal Medicine, 151(4), 264-270.

Mustian, B. K. M., Katula, J. A., Gill, D. L., Roscoe, J. A., Lang, D., Murphy, K., \& Tai, K. (2004). Tai Chi Chuan, healthrelated quality of life and self-esteem: a randomized trial with breast cancer survivors. Support Care Cancer, 12(12), 871-876. https://doi.org/10.1007/s00520004-0682-6

Rizkiana, U., \& Retnaningsih, R. (2012). Penerimaan Diri Pada Remaja Penderita Leukemia. Jurnal Ilmiah Psikologi, 2(2).

Saniatuzzulfa, R., Retnowati, S., \& Magister Profesi Psikologi Fakultas Psikologi 
Universitas Gadjah Mada, P. (2015). Program "Pasien PANDAI" untuk Meningkatkan Optimisme Pasien Kanker. Gadjah Mada Journal of Professional Psychology, 1(3), 163-172.

Schunemann, H. J., Oxman, A. D., Higgins, J. P., Vist, G. E., Glasziou, P. P., \& Guyatt, G. H. (2008). Presenting Results and "Summary of Findings" Tables. Cochrane Handbook for Systematic Reviews of Interventions: Cochrane Book Series, 335357.

https://doi.org/10.1002/9780470712184.ch 11

Speca, M., Carlson, L. E., Mackenzie, M. J., \& Angen, M. (2014). Mindfulness-Based Cancer Recovery. Mindfulness-Based Treatment Approaches, 12(2), 293-316. https://doi.org/10.1016/B978-0-12416031-6.00013-X

Tang, S. T., Chang, W. C., Chen, J. S., Chou, W. C., Hsieh, C. H., \& Chen, C. H. (2016). Associations of Prognostic Awareness/acceptance with Psychological Distress, Existential Suffering, and Quality of Life in Terminally Ill Cancer Patients' Last Year of Life. Psycho-Oncology, 462(25), 455-462.

https://doi.org/10.1002/pon.3943
Tighe, J. (2016). Relaxation techniques. $B B C$ Health, (360), 3164. Retrieved from http://www.bbc.co.uk/health/emotional_he alth/mental_health/coping_relaxation.shtm 1

Toussaint, L., Barry, M., Bornfriend, L., \& Markman, M. (2014). Restore: The Journey Toward Self-Forgiveness: A Randomized Trial of Patient Education on Self-Forgiveness in Cancer Patients and Caregivers. Journal of Health Care Chaplaincy, 20(2), 54-74. https://doi.org/10.1080/08854726.2014.90 2714

Zielazny, P., Biedrowski, P., Lezner, M., Uzdrowska, B., Błaszczyk, A., \& Zarzeczna-Baran, M. (2013). Acceptance of Illness, beliefs about pain control and coping strategies among patients scheduled for surgery for osteoarthritis of the spine. Postepy Psychiatrii i Neurologii, 22(4), 251-258. Retrieved from http://www.embase.com/search/results?sub action=viewrecord $\&$ from=export $\& \mathrm{id}=\mathrm{L} 37$ 3784862\%5Cnhttp://limo.libis.be/resolver? $\&$ sid=EMBASE\&issn=12302813\&id=doi: \&atitle $=$ Acceptance+of + Illness $\% 2 C+$ belie fs+about+pain+control+and+coping+strate gies+among+patients+schedule 